\title{
A STUDY OF FUTURE OPPORTUNITIES AND CHALLENGES IN DIGITAL HEALTHCARE SECTOR: CYBER SECURITY VS. CRIMES IN DIGITAL HEALTHCARE SECTOR
}

\author{
Avani Rachh \\ Somaiya Institute, India \\ Correspondence: avanir@somaiya.edu
}

\section{ABSTRACT}

\section{OBJECTIVE}

The current study is to understand the opportunities for and challenges faced by digital healthcare sector. The aim of the study is to suggest measures for securing data and information collected by the sector plus have safer online transactions.

\section{DESIGN AND SETTING}

The secondary data was collected from reliable sources. The primary data was collected online. The quantitative and qualitative analysis was done on data. The data was statistically analysed for this research article.

\section{RESULTS}

Even though healthcare sector has spent on digital health and cybersecurity but still the number of cybercrime cases have increased. An attempt is made to understand the factors that can influence the number of cybercrime cases.

\section{CONCLUSION}

The healthcare sector has opportunities in digital healthcare field in the current pandemic situation. At the same time, it has challenges to reduce the cybercrime cases as hackers are stealing confidential data and to take stringent measures to reduce the same.

\section{KEYWORDS}

Healthcare Sector, Digital Healthcare Sector, Opportunities, Challenges

\section{INTRODUCTION}

Healthcare sector has helped humankind in present covid pandemic situation. People are working from home but some sectors have opened up. People have to travel from their home to work and are prone to be infected. In some

countries, the number of cases has increased and governments were forced to announce lockdown again. The health of citizens is more important. More people have started using digital healthcare facilities like mobile applications to contact doctors and order medicines online. Due to current pandemic scenario, digital 
healthcare sector has many opportunities and challenges like safeguarding online data.

Digital healthcare is an important part of healthcare system. It helps patients who are at home to connect with doctors. It reduces costs due to use of information, communication and technology. The medical records can be stored and accessed electronically known as Electronic Health Records (EHR). Mobile applications help to monitor health conditions. Digital healthcare has been used in the past also but now it has gained more importance than traditional healthcare systems, as it provides effective and ethical healthcare. [1]

Introduction of technology in everyday activities has provided many opportunities and challenges to data and information including infrastructure. [2] While in current and post Covid situations digital healthcare is most affected. The growth has increased multi-fold and will grow rapidly in the future. [3] Digital healthcare market is estimated to grow rapidly from USD \$106 billion in 2019 to USD \$640 billion in 2026. [4]

Healthcare sector has taken lot of burden in 2020 due to the Covid pandemic. It has given a boost to the digital healthcare sector and at the same time, new challenges are springing up. One of the main challenges is to safeguard data as we use digital platforms for health. [5] The other challenges are privacy, data breaches, data security, identity theft and cyber-attacks. [6]

The United States of America has dedicated acts for protecting health records and data privacy. Very few countries like United Kingdom, European Union, Australia, Canada, Singapore, Japan and New Zealand have specific rules, regulations, provisions or guidelines in their laws to safeguard personal information and data including electronic documents plus privacy. The authors have divided the health records in 3 groups based on sensitivity level. The first group is normal which can contain personal plus social data and identity theft can be the possible crime. The second group is called sensitive and includes financial information and has risk of frauds. The last cluster is named highly sensitive and comprises of data related to health risks plus clinical diagnoses. The possible crime for the third group could be extortion. Fifty-eight percentages of data breaches are done by insiders. With opportunities comes the threats like hacking, ransomware, phishing plus privilege abuse and challenges to Electronic Medical Records (EMR) infrastructure or system. [7]
The healthcare software developing companies have to take extra precautions to safeguard personal data collected by them. The issues elevated in such conditions are ethical, moral plus legal in nature. The companies have to follow confidential guidelines and deal with challenges like cyber privacy and security. [8]

\section{CYBER CRIME CASES RELATED TO HEALTHCARE SECTOR}

In 2019, among the top five Indian cybercrime cases the major one was a hacking attacks on Indian healthcare website. The hacker stole 68 lakh records of doctors and patients. [9] In September 2020, Chinese hackers stole Spanish Research Centre's information related to Covid-19 vaccine. [10] In September 2020, German hospital and Universal Health Services (UHS) health system at 400 locations faced ransomware attacks. The five healthcare organisations reported that their data was stolen and available on the dark web by different hacker groups. [11] Many cybercrime cases are reported in India.

\section{METHODS}

\section{RESEARCH OBJECTIVES}

- To find out current situation of digital healthcare sector.

- To analyse global healthcare plus healthcare cybersecurity fundings and global cybersecurity market.

- To analyse corporate funding for digital health.

- To find out number of cybercrime cases reported in India.

- To find out cybercrime cases relating to healthcare sector.

- To analyse factors affecting security measures or precautions.

\section{RESEARCH METHODOLOGY}

The quantitative and qualitative research analysis are done. Primary and secondary data are collected. Secondary data are collected from different sources. [12] [13] [14] The questionnaire method was used for primary data collection. The primary data was collected online using Google Form. The sample size of primary data is 111 .

\section{DATA ANALYSIS}

Microsoft Excel and statistical analysis software like PSPP, JASP (R based) are used for data analysis like frequency distribution, charts, correlation and factor analysis. [15] The 
Descriptive Analysis like Mean, Standard Deviation and Percentages were also computed.

\section{HYPOTHESES}

Independent Sample T-Test is used to analyse the primary data.

- $H_{\circ}$ : To identify responses about willingness to provide information using mobile phone with respect to gender.

- $\quad H_{\circ}$ : To identify the responses about "There should be new laws to protect privacy on the Internet" with respect to gender.

Correlation is used to identify relationship between variables.

- $\mathrm{H}_{\circ}$ : The correlation between Annual Global Healthcare Funding and Annual Global Corporate Funding for Digital Health is not statistically significant.

- $H_{\circ}$ : The correlation between Annual Global Healthcare Funding and Annual Global Healthcare CyberSecurity Funding is not statistically significant.

- $\mathrm{H}_{\circ}$ : The correlation between Annual Global Corporate Funding for Digital Health and Annual Global Healthcare CyberSecurity Funding is not statistically significant.

- $\mathrm{H}_{\circ}$ : The correlation between Annual Global Corporate Funding for Digital Health and Number of Cyber Crime Cases Reported in India is not statistically significant.

- $\mathrm{H}_{\circ}$ : The correlation between Annual Global Cybersecurity Market and Number of Cyber Crime Cases Reported in India is not statistically significant.

\section{RESULTS}

The annual global healthcare funding has increased from $\$ 34,361$ million from 2016 to $\$ 80,612$ million in 2020 , while number of annual global healthcare deals have increased from 4,140 to 5,523 from 2016 to 2020. Seventy-eight percentage of males felt privacy is more important than convenience, while $91 \%$ of females felt the same.

The Null Hypothesis, to identify responses about willingness to provide information using mobile phone with respect to gender was accepted as significance (2-tailed) value is more than 0.05 at $95 \%$ Confidence Level. The Null Hypothesis, to identify the responses about "There should be new laws to protect privacy on the Internet" with respect to gender was accepted as significance (2-tailed) value is more than 0.05 at $95 \%$ Confidence Level.

The strong positive correlation was found at 95\% level for all the hypotheses statements. Therefore, we can say that there is correlation between all the mentioned variables. It means that even after spending on security, the number of cyber crime cases in India are increasing. It is necessary to overcome these challenges.

\section{FACTOR ANALYSIS}

The Factor Analysis was done to understand the security measures or precautions taken by respondents to safeguard the data and information from cyber fraudsters, etc. The respondents were requested to provide their responses for the following statements relating to information security:

1) $\mathrm{V} 1=\mathrm{I}$ respond to messages asking for urgent action due to security reasons.

2) V2 = I check padlock icon of the browser.

3) $\vee 3=$ I click on links from any unknown person.

4) $\vee 4=$ I share my financial or personal information by email or text message.

5) $\quad \mathrm{V} 5=1$ destroy the pin mailer after memorising the pin and/or change the pin after the first usage.

6) V6 = I keep my pin and ATM card /debit card /credit card together.

7) $\quad$ V7 = I disclose my internet banking password with anybody including my family members.

8) $\quad$ $88=1$ respond to online offers that require me to provide my account details "for verification".

9) V9 = I always check the last log-in to my Internet Banking account.

10) $\vee 10=I$ use the virtual keyboard/keypad to enter the user name/login and password for online banking.

\section{a) Preliminary Analysis}

As per Table 1, determinant value is .253, which is more than .00001 . Hence, multicollinearity is not a problem for these data. So, no need to eliminate any questions. The Pearson's Correlation Heatmap (Figure 1) shows correlation between the variables in graphical way. 


\begin{tabular}{|c|c|c|c|c|c|c|c|c|c|c|}
\hline $\begin{array}{l}\text { VARIABL } \\
\text { E }\end{array}$ & V1 & V2 & V3 & V4 & V5 & V6 & V7 & V8 & V9 & V10 \\
\hline 1. $\mathrm{Vl}$ & - & & & & & & & & & \\
\hline 2. V2 & 0.16 & - & & & & & & & & \\
\hline 3. V3 & 0.171 & 0.059 & - & & & & & & & \\
\hline 4. V4 & 0.093 & -0.1 & $\begin{array}{l}0.352^{* *} \\
*\end{array}$ & - & & & & & & \\
\hline 5. V5 & 0.019 & 0.125 & -0.01 & 0.09 & - & & & & & \\
\hline 6. V6 & 0.067 & $0.188^{*}$ & 0.169 & 0.119 & $0.222^{*}$ & - & & & & \\
\hline 7. V7 & -0.001 & -0.083 & $0.29 * *$ & $\begin{array}{l}0.341^{* *} \\
*\end{array}$ & 0.052 & $0.306^{* *}$ & - & & & \\
\hline 8. V8 & 0.097 & -0.037 & $0.38^{* * *}$ & $0.252^{* *}$ & 0.008 & $\begin{array}{l}0.322^{* *} \\
*\end{array}$ & $\begin{array}{l}0.433^{* *} \\
*\end{array}$ & - & & \\
\hline 9. V9 & 0.12 & $0.284^{* *}$ & 0.05 & -0.17 & 0.18 & 0.141 & 0.09 & 0.105 & - & \\
\hline 10. $\vee 10$ & 0.07 & $0.271^{* *}$ & $0.214^{*}$ & -0.078 & 0.05 & $0.239 *$ & 0.127 & 0.143 & $0.292^{* *}$ & - \\
\hline
\end{tabular}

$* p<.05,{ }^{* *} p<.01, * * * p<.001 \quad$ Determinant $=0.253$

TABLE 4: COMPONENT LOADINGS

\begin{tabular}{|l|l|l|l|l|l|}
\hline & PC1 & PC2 & PC3 & PC4 & UNIQUENESS \\
\hline V1 & & & & 0.856 & 0.256 \\
\hline V2 & & 0.608 & & & 0.45 \\
\hline V3 & 0.633 & & & & 0.407 \\
\hline V4 & 0.552 & -0.455 & & & 0.332 \\
\hline V5 & & & 0.906 & & 0.174 \\
\hline V6 & 0.478 & & & & 0.47 \\
\hline V7 & 0.767 & & & & 0.378 \\
\hline V8 & 0.76 & & & & 0.41 \\
\hline V9 & & 0.693 & & & 0.489 \\
\hline V10 & & 0.718 & & & 0.406 \\
\hline
\end{tabular}

Note: Applied rotation method is varimax. 




TABLE 2: KMO AND BARTLETT'S TEST

\begin{tabular}{|l|l|l|}
\hline \multicolumn{2}{|l|}{ Kaiser-Meyer-Olkin (KMO) Test (Overall) } & .673 \\
\hline & Chi-Square & \\
\hline \multirow{2}{*}{ Bartlett's Test of Sphericity } & Df & 145.385 \\
\cline { 2 - 3 } & Sig. & 45 \\
\hline
\end{tabular}

Kaiser-Meyer-Olkin (KMO) test value is .673 i.e. more than .5, factor analysis is suitable as per table 2, as the mentioned so acceptable according to table 2. Therefore, factor Bartlett's test significance value is $<.001$.

analysis is possible for these variables. In the same way 
b) Factor Extraction

There are 10 components in initial eigenvalues and 4 components after rotation. There is slight percentage difference between initial eigenvalues and after rotation as per table 3. Extraction Method used is Principal Component Analysis to get figures mentioned in the tables 3 and 4. At the initial stage, all components are treated equal and value 1 is given.

TABLE 3: TOTAL VARIANCE EXPLAINED

\begin{tabular}{|l|l|l|l|l|l|l|}
\hline \multicolumn{3}{|c|}{ INITIAL EIGENVALUES } & \multicolumn{3}{l|}{ ROTATION SUMS OF SQUARED LOADINGS } \\
\hline & Total & $\%$ of Variance & Cumulative \% & Total & \% of Variance & Cumulative \% \\
\hline 1 & 2.38 & $23.80 \%$ & $23.80 \%$ & 2.19 & $21.90 \%$ & $21.90 \%$ \\
\hline 2 & 1.72 & $17.20 \%$ & $41.00 \%$ & 1.71 & $17.10 \%$ & $39.00 \%$ \\
\hline 3 & 1.1 & $11.00 \%$ & $52.00 \%$ & 1.17 & $11.70 \%$ & $50.70 \%$ \\
\hline 4 & 1.03 & $10.30 \%$ & $62.30 \%$ & 1.16 & $11.60 \%$ & $62.30 \%$ \\
\hline 5 & 0.8 & $8.00 \%$ & $70.30 \%$ & & & \\
\hline 6 & 0.76 & $7.60 \%$ & $77.90 \%$ & & & \\
\hline 7 & 0.65 & $6.50 \%$ & $84.40 \%$ & & & \\
\hline 8 & 0.6 & $6.00 \%$ & $90.40 \%$ & & & \\
\hline 9 & 0.49 & $4.90 \%$ & $95.30 \%$ & & & \\
\hline 10 & 0.47 & $4.70 \%$ & $100.00 \%$ & & & \\
\hline
\end{tabular}

TABLE 5: COMPONENT CHARACTERISTICS

\begin{tabular}{|l|l|l|l|} 
& EIGENVALUE & PROPORTION VAR. & CUMULATIVE \\
\hline PC1 & 2.382 & 0.238 & 0.238 \\
\hline PC2 & 1.72 & 0.172 & 0.41 \\
\hline PC3 & 1.1 & 0.11 & 0.52 \\
\hline PC4 & 1.025 & 0.103 & 0.623 \\
\hline
\end{tabular}

As per tables 4 and 5 as well as figures 2 plus 3, generated FIGURE 2: SCREEN PLOT by the analysis software based on $\mathrm{R}$ has extracted 4 factors using varimax rotation method. The loadings less than .45 are suppressed in output. The four factors or component groups i.e. PC1/RC1 to PC4/RC4 are named below:

1) $\mathrm{PCl} / \mathrm{RC} 1=$ Careless about security.

2) $\mathrm{PC} 2 / \mathrm{RC} 2=$ Check and use online security features.

3) $\mathrm{PC} 3 / \mathrm{RC} 3=$ Destroy mail after changing pin.

4) PC4/RC4 = Respond to messages for security purpose.

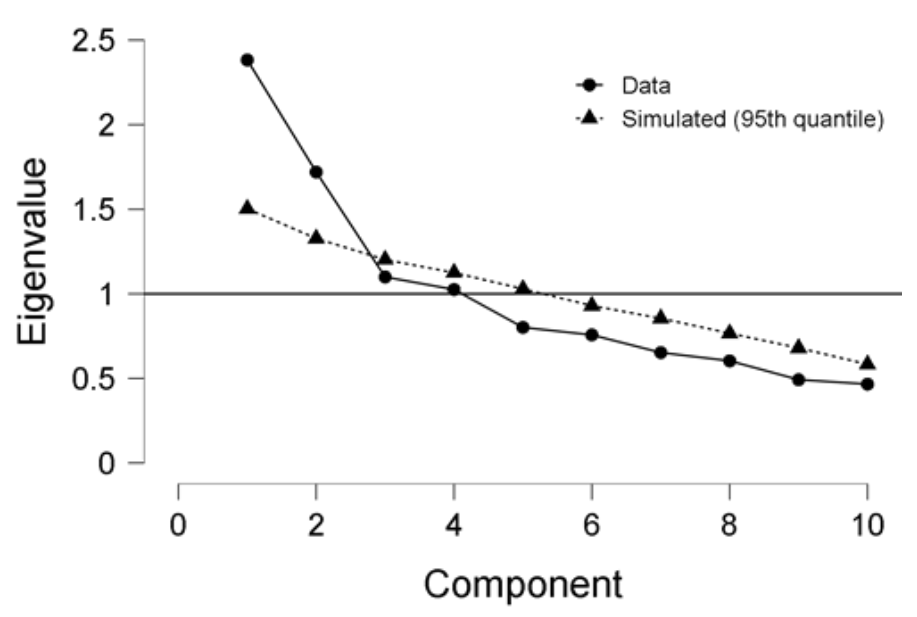




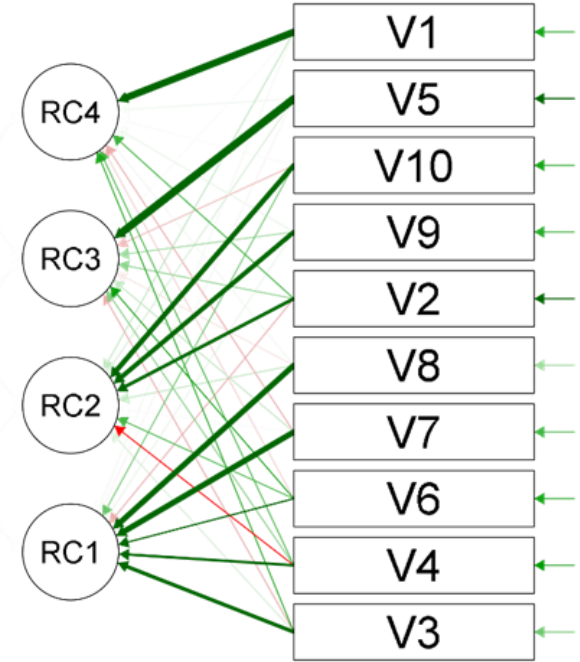

\section{DISCUSSION:}

The aim of the current study is to research future opportunities and challenges faced by digital healthcare sector. The qualitative analysis was undertaken to understand the problems faced by the same sector. They have reported many cybercrime cases worldwide. In case of India, also the number of cybercrime cases have risen over the years.

The quantitative analysis was also done to find out the present scenario of digital healthcare sector. The questionnaire was developed and primary data was collected. As per the results, the respondents were willing to provide information using mobile phones. They also wanted new laws to protect privacy on the internet. The cyber-attacks will have negative impact on privacy of patients. [16]

The secondary data related to Annual Global Healthcare Funding, Annual Global Corporate Funding for Digital Health, Annual Global Healthcare CyberSecurity Funding, Annual Global Cybersecurity Market and Number of Cyber Crime Cases Reported in India was also collected for hypotheses testing. The aim was to test the correlations between them. It is generally assumed that with the increase in funding for healthcare sector plus more corporate funding for digital health including increase in cybersecurity funding globally would reduce the number of cybercrime cases, but that is not happening. The cyberattacks have increased during the current pandemic period. [17] The question arises then what should be done to bring down the number of cybercrime cases? The answer would help to overcome the challenges in digital healthcare sector.

The factor analysis was conducted on the ten statements regarding information security mentioned in the questionnaire. The respondents provided data that helped to know the security measures or precautions taken by them to protect the data and information from different types of cybercrimes. The four factors were extracted namely careless about security, check and use online security features, destroy mail after changing pin plus respond to messages for security purpose. The further research can be done based on the four mentioned factors. The war is between cyber security and crimes in digital healthcare sector, where cyber security will win only when the number of cybercrime cases would reduce.

\section{LIMITATIONS}

The study is restricted to secondary and statistical data available up to 2020. The National Crime Records Bureau has provided data up to 2019 only. Sample size (111) of primary data is limited due to Covid pandemic, lack of time, resources and an on ongoing process.

\section{IMPLICATIONS}

The healthcare industry has to safeguard the data by regularly monitoring the systems. As we upload more records and detailed personal data of people in the online system, the attackers would like to steal or hack the data. The healthcare sector has to develop Alert Intelligent Systems (AIS) to know whenever an attacker tries to attack the digital resources, so that the system can automatically counter. [18] They have to develop a business continuity and recovery plan plus report the same to cybercrime cell for further investigation. If attackers feel that they will be punished with imprisonment and or fine then only it will be a deterrent and help in reducing the number of cybercrime cases.

\section{CONCLUSION}

The cybercrime cases have increased even after spending on cyber security measures. It is important to have security controls at all levels to protect personal information and medical records of people. It is important to create awareness among people about cyber security. Healthcare sector and government authorities have to do these on a consistent basis. It requires more research to be 
done and create a crime mapping to understand plus overcome the challenges.

\section{References}

1. Edirippulige S, Senanayake B. Professional Practices for Digital Healthcare. Opportunities and Challenges in Digital Healthcare Innovation [Internet]. 2020 [cited 2021 April 11];97-112. Available from: https://www.igiglobal.com/gateway/chapter/254968

2. Gercke, M. Understanding cybercrime: phenomena, challenges and legal response, ITU Telecommunication Development Bureau [Internet]. 2012 [cited 2021 April 25]. Available from:

http://www.itu.int/ITU-

D/cyb/cybersecurity/docs/Cybercrime legislation EV6.pdf

3. CB Insights. App.cbinsights.com [Internet]. 2021 [cited 20 April 2021]. Available from:

https://app.cbinsights.com/research/real-worldevidence-healthcare-media/

4. Sumant Ugalmugle, Rupali Swain. Digital Health Market Size By Technology [Tele-healthcare \{Telecare (Activity Monitoring, Remote Medication Management), Telehealth (LTC Monitoring, Video Consultation)\}, mHealth $\{$ Wearables (BP Monitors, Glucose Meter, Pulse Oximeter, Sleep Apnea Monitors, Neurological Monitors), Apps (Medical, Fitness)\}, Health Analytics, Digital Health System (EHR, eprescribing System)], By Component [Hardware, Software, Services], Industry Analysis Report, Regional Outlook, Application Potential, Price Trends, Competitive Market Share \& Forecast, 2020 - 2026 [Internet]. Global Market Insights, Inc. Global Market Insights, Inc.; 2020 [cited 2021 April 20]. Available from: https://www.gminsights.com/industry-analysis/digitalhealth-

market\#: :text=Digital\%20Health\%20Market\%20size\%2 Owas, the\%20digital\%20health\%20industry\%20growth.

5. Siriwardhana $Y$, Gür $G$, Ylianttila $M$, Liyanage $M$. The role of $5 G$ for digital healthcare against COVID-19 pandemic: Opportunities and challenges. ICT Express [Internet]. 2020 Nov [cited 2021 April 20]; Available from:

https://www.sciencedirect.com/science/article/pii/s2 405959520304744?via\%3Dihub

6. Mukul. Patients' Privacy \& Data Threat in Digital Era. eHealth Magazine [Internet]. Eletsonline.com. 2020 [cited 2021 April 12]. Available from: https://ehealth.eletsonline.com/2020/02/patientsprivacy-data-threat-in-digital-era/amp/

7. Chernyshev M, Zeadally S, Baig Z. Healthcare Data Breaches: Implications for Digital Forensic Readiness. Journal of Medical Systems [Internet]. 2018 Nov 28 [cited 2021 April 29];43(1). Available from: https://link.springer.com/article/10.1007/s10916-0181123-2\#citeas

8. Lee D, Yoon SN. Application of Artificial IntelligenceBased Technologies in the Healthcare Industry: Opportunities and Challenges. International Journal of Environmental Research and Public Health [Internet]. 2021 Jan 1 [cited 2021 April 29];18(1):271. Available from: https://www.mdpi.com/1660-4601/18/1/271/htm

9. Dutta, P. 5 Biggest Cyber Attacks in India | Everything You Need to Know | Kratikal [Internet]. Kratikal Blog. 2019 [cited 2021 April 5]. Available from:

https://www.kratikal.com/blog/5-biggest-cyberattacks-in-india/

10. Significant Cyber Incidents | Center for Strategic and International Studies [Internet]. Csis.org. 2021 [cited 2021 April 15]. Available from:

https://www.csis.org/programs/strategictechnologies-program/significant-cyber-incidents

11. Application Security in the Rapid Digital Transformation Age: 2021 Threatscape [Internet]. @BrightTALK. 2021 [cited 2021 April 5]. Available from: https://www.brighttalk.com/webcast/17474/465278/a pplication-security-in-the-rapid-digital-transformationage-2021-threatscape

12. CB Insights. App.cbinsights.com [Internet]. 2021 [cited 20 April 2021]. Available from:

https://app.cbinsights.com/research/report/industriestech-shaping-world-post-covid/

13. Nithin Thomas Prasad. Corporate Funding for Solar Slid Globally in 1H 2020 But, It Could Have Been Worse Mercom India [Internet]. Mercom India. 2020 [cited 2021 April 5]. Available from:

https://mercomindia.com/corporate-funding-solarslid-globally/

14. Crime In India | National Crime Records Bureau [Internet]. Ncrb.gov.in. 2020 [cited 2021 March 5]. Available from: https://ncrb.gov.in/en/crime-india

15. Field A. C8057 (Research Methods II): Factor Analysis on SPSS Factor Analysis Using SPSS [Internet].; [cited 
2021 March 5]. Available from:

http://www.discoveringstatistics.com/docs/factor.pdf

16. Mrcela M, Vuletic I. Healthcare, Privacy, Big Data and Cybercrime: which one is the weakest link? Annals of Health Law [Internet]. 2018 [cited 2021 August 30];27 (2). Available from:

https://lawecommons.luc.edu/annals/vol27/iss2/9

17. Lallie HS, Shepherd LA, Nurse J, Erola A, Epiphaniou G, Maple C, Bellekens X. Cyber security in the age of COVID-19: A timeline and analysis of cyber-crime and cyber-attacks during the pandemic. Computers \& Security [Internet]. June 2021 [cited 2021 August 30];105. Available from:

https://www.sciencedirect.com/science/article/pii/sO 167404821000729

18. Guiora A. N. Cybersecurity: Geoplotics, law, and policy. London: Routledge, Taylor \& Francis Group; 2017. 